\title{
Trophy Hunting Versus Ecotourism as a Conservation Model? Assessing the Impacts on Ungulate Behaviour and Demographics in the Ruaha-Rungwa Ecosystem, Central Tanzania
}

\author{
Kwaslema Malle Hariohay ${ }^{1,2}$, Craig R. Jackson ${ }^{3}$, Robert D. Fyumagwa ${ }^{1}$ \& Eivin Røskaft ${ }^{2}$ \\ ${ }^{1}$ Tanzania Wildlife Research Institute, P.O.Box 661, Arusha, Tanzania \\ ${ }^{2}$ Department of Biology, Norwegian University of Science and Technology, Realfagbygget, No-7491, Trondheim, \\ Norway \\ ${ }^{3}$ Department of Terrestrial Ecology, Norwegian Institute for Nature Research, Trondheim, Norway \\ Correspondence: Kwaslema Malle Hariohay, Tanzania Wildlife Research Institute, P.O. Box 661, Arusha, \\ Tanzania. Tel: 255-769-190-099. E-mail: alexmalle2007@yahoo.com
}

Received: March 17, 2018

Accepted: April 10, 2018

Online Published: April 20, 2018

doi:10.5539/enrr.v8n2p33

URL: https://doi.org/10.5539/enrr.v8n2p33

\begin{abstract}
Trophy hunting may influence wildlife populations in many ways, but these effects have received little consideration in many of Africa's protected areas. We assessed the effects of trophy hunting on group size, behaviour, flight initiation distance, sex ratio and calf recruitment rate in two model species, impala (Aepyceros melampus) and greater kudu (Tragelaphus strepsiceros), in Rungwa Game Reserve (RGR), Tanzania. The adjoining Ruaha National Park (RNP) served as a control site, since only ecotourism is permitted. Road transects were driven and data recorded immediately upon sighting animals. Both impala and greater kudu had higher flight initiation distances, smaller group size, lower calf recruitment rates and higher levels of vigilance behaviour in RGR compared to those in RNP. Sex ratios did not differ between the two areas. The observed differences are ascribed to the direct and indirect effects of trophy hunting in RGR. Low calf recruitment rates in RGR are of concern, as this may directly compromise population growth rates. Long-term studies may therefore be required to assess how hunted populations are affected by different hunting intensities and at what point this may threaten population persistence.
\end{abstract}

Keywords: Calf recruitment, flight initiation distance, group size, sex ratio, trophy hunting

\section{Introduction}

Anthropogenic disturbances affect wildlife populations in many ways (Christiane Averbeck, Apio, Plath, \& Wronski, 2009; Lindsey et al., 2013; Lunde, Bech, Fyumagwa, Jackson, \& Røskaft, 2016; Matthias Waltert, Meyer, \& Kiffner, 2011; Mathias Waltert et al., 2008). In response, animals may exhibit behavioural changes to minimise potentially negative impacts (Hunninck et al., 2017; Nyahongo, 2008; Tingvold et al., 2013). Vigilance, for example, may increase in response to threatening processes (Nyahongo, 2008; Tingvold et al., 2013; Matthias Waltert et al., 2011) and although this may reduce mortality risk, an increase in vigilance incurs costs as time spent on fitness-increasing behaviours is lost to vigilance (Holmern, Setsaas, Melis, Tufto, \& Røskaft, 2016). In this way, behavioural modifications carried out by human activities can have indirect negative population-level effects. Particularly invasive disturbances, however, may lead to direct changes in demographic parameters such as sex ratio and recruitment of young (Christiane Averbeck et al., 2009; Love, Chin, Wynne-Edwards, \& Williams, 2005; Lunde et al., 2016; Tuomainen \& Candolin, 2010). In combination, such processes have the ability to affect a population's reproductive potential and thereby its probability of persistence.

The rapidly increasing global human population exacerbates the extent and severity of negative anthropogenic effects wildlife populations are exposed to. In response, protected areas are playing an increasingly important role in safeguarding ecosystems and the biodiversity they support. In regions with poor rural communities, however, the natural resources within protected areas represent a valuable source of food (plants and animals), timber for construction, firewood, etc. As a result, human population growth is often particularly rapid in areas immediately alongside protected areas (Kideghesho, 2015; Kideghesho, Nyahongo, Hassan, Thadeo, \& Mbije, 
2006). Protected areas need to be financially viable and, in this regard, may employ a variety of revenue-generating strategies. Strategies may vary greatly and have equally disparate effects on the ecosystems they ultimately seek to conserve. Two strongly opposing, yet frequently implemented models involve either a "national park" approach, where only non-consumptive ecotourism-type activities are permitted, or a "game reserve" management type that permits trophy hunting of, usually, large mammals. While both have the capacity to generate considerable revenue, their potential effects on wildlife populations differ considerably (Hunninck et al., 2017).

In many wild populations, rates of hunting-induced mortality are often substantially higher than natural mortality rates for adult animals (Allendorf \& Hard, 2009). Hunted individuals of any wild mammal will, by definition, have a lower reproductive output. Trophy hunting selection and harvesting consequently have considerable effects on the evolution of adult characteristics, particularly the characteristics of prime-aged adults (Milner, Nilsen, \& Andreassen, 2007; Whitman, Starfield, Quadling, \& Packer, 2004). Phenotypic characteristics such as body size, colour, horns and antlers are used as selective elements of ungulates during hunting practices (Bateman \& Fleming, 2014; Festa-Bianchet \& Apollonio, 2003; Loveridge, Searle, Murindagomo, \& MacDonald, 2007; Milner et al., 2007). Under such scenarios, hunting can lead to unintended selection by reducing the frequency of phenotypes that are favoured by the females for mate choice (Allendorf \& Hard, 2009; Ginsberg \& Milner Gulland, 1994; Jarman \& Jarman, 1973). A more direct and serious effect, however, can result in altered age structures, sex ratios and reduced population sizes due to poorly regulated hunting practices (Tuomainen \& Candolin, 2010). Such variables directly affect a population's reproductive capacity and may therefore influence population trends over time.

Tourist hunting contributes large amounts of money to economies of poor countries such as Tanzania, and it is therefore considered an important industry (Gereta, 2010). A positive effect of tourist hunting is that it contributes to control of wildlife populations, as only animals with large populations are hunted given proper quota allocation and adhered to it (Allendorf \& Hard, 2009; Christiane Averbeck et al., 2009). The money accrued from hunters through hunting licenses may be put back into programmes that enhance wildlife and environmental conservation (Allendorf \& Hard, 2009; Baldus \& Cauldwell, 2004). Thus, if hunting is well regulated, sustainable sport hunting can play an important role in wildlife protection and conservation (Balakrishnan \& Ndhlovu, 1992; Caro et al., 1998). Direct conservation benefits, as well as ensuring longer-term population persistence through managing land under a consumptive management regime, frequently remain unclear. Furthermore, the direct effects of consumptive activities on animal populations, in contrast to those of an ecotourism model, remain unclear.

\subsection{Objective}

The objective of this study was to assess the effect of hunting on two common species in Tanzania's Ruaha-Rungwa ecosystem, the impala (Aepyceros melampus) and the greater kudu (Tragelaphus strepsiceros). This contiguous ecosystem is managed in two separate parts: Ruaha National Park (RNP), where only non-consumptive ecotourism is permitted, and Rungwa Game Reserve (RGR), which derives most of its income from trophy hunting. For both antelope species, we assessed flight initiation distance (FID), sex ratio, recruitment rate, group size and different behaviours in relation to protected area type. We also tested sex ratio, group size, vigilance and feeding behaviour, as well as FID, in relation to habitat type.

\subsection{Hypotheses}

We hypothesised that impala and kudu in the RGR would show greater FID, smaller group size, more female-skewed sex ratios, lower recruitment rates and higher vigilance behaviour compared to individuals in RNP. We also hypothesised that habitat type would have no effect on group size, behaviour, sex ratio, recruitment and flight initiation distance.

\section{Methods}

\subsection{Study Areas}

This study was conducted in Ruaha National Park (RNP) and Rungwa Game Reserve (RGR) during the 2016 and 2017 hunting seasons, which start in July and end in December each year. The two protected areas (PAs) are located in a single continuous ecological ecosystem (Ruaha-Rungwa), covering more than $43,000 \mathrm{~km}^{2}$ in Central Tanzania (Figure 1). These PAs fall under different management authorities; RNP falls under Tanzania National Parks (TANAPA), and RGR falls under Tanzania Wildlife Management Authority (TAWA). In RNP, only non-consumptive activities, such as photographic safaris and game viewing, are permitted, while the major tourism activity in RGR is trophy hunting. In both management regimes, there are high densities of animals, as 
well as a high species richness (biodiversity) (MNRT, 2011). The human population growth rate around RNP is $4 \%$ annually (URT, 2013). Villages surrounding such sites are increasingly expanding in response to a demand for land and natural resources to alleviate food shortages, reduce poverty and improve livelihood. Wildlife crimes such as poaching occur at a high degree, particularly in RGR (Hariohay, Fyumagwa, Kideghesho, \& Røskaft, 2017).

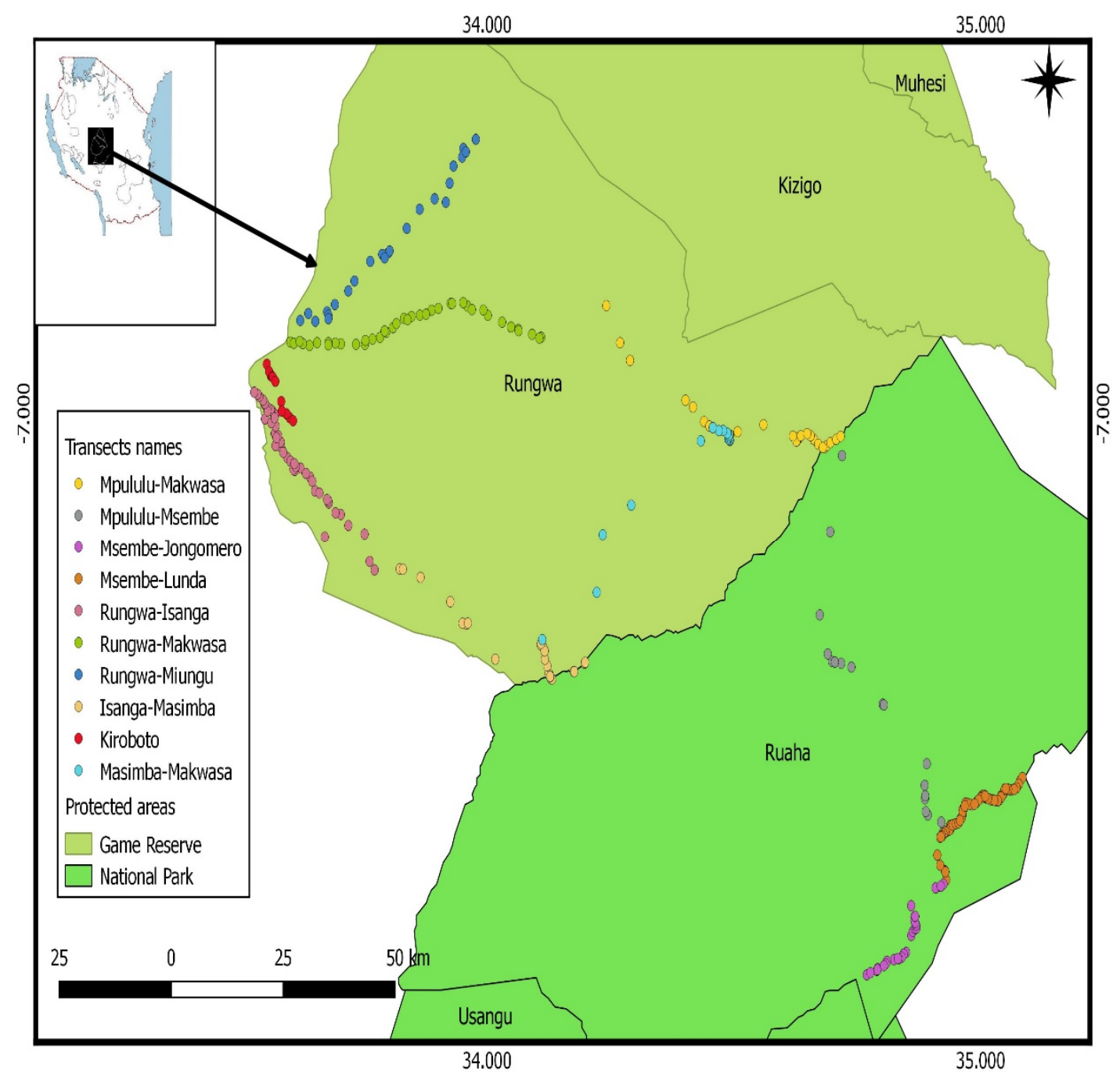

Figure 1. Transects driven in Rungwa Game Reserve and Ruaha National Park

\subsection{Study Species}

Impala is a medium-sized African antelope, and individuals range between 120-160 cm in length (Averbeck, 2002). Impala are sexually dimorphic antelopes, where only males are horned and are noticeably larger than females (Jarman \& Jarman, 1973; Kie, 1999; Lunde et al., 2016). Males stand approximately 75-92 cm tall and weigh 53-76 kg, while females weigh 40-53 kg (C Averbeck, 2002; Christiane Averbeck et al., 2009). Impala inhabit savannah grasslands and woodlands in close proximity to water sources. Impala are mixed foragers of grasses, forbs, monocots, dicots and foliage (Marshal, Grange, \& Marneweck, 2012; Wronski, 2002). Impala switch habitats between seasons due to variability of food availability (Marshal et al., 2012; Wronski, 2002). They live in three distinct social groups: 1) female herds with a territorial male, 2) bachelor herds (males in different age groups only) and 3) single territorial males. Their gestation period is six to seven months.

Greater kudu males are considerably larger than females and have spiral horns. Male head-body length is approximately 185-245 cm (Hoffmann, 2016). Greater kudus occur in woodlands, as they are browsers that eat leaves 
and shoots. In the dry season, they eat wild watermelons and other fruits for their liquid content and the natural sugars that they provide (de Garine-Wichatitsky, Fritz, Gordon, \& Illius, 2004). Male kudus can be found in bachelor groups, but they are more likely to be solitary (Hoffmann, 2016; Kie, 1999). Their dominance displays tend not to last long and are generally fairly peaceful, consisting of one male making himself look big by making his hair stand on end. Males are seen with females only in the mating season, when they form groups of 5-15 kudus, including offspring (Hoffmann, 2016). Calves grow quickly and are independent of their mothers starting at six months old.

\subsection{Data Collection Techniques}

\subsubsection{Transects}

Fixed transects were established and driven along existing major roads inside RNP and RGR, and off-road driving was done only when it was necessary to come closer to a group of individuals (Okello \& Yerian, 2009) (Fig. 1). We used a Land Rover pickup driven at a speed of $10-20 \mathrm{~km} / \mathrm{h}$ with two observers and one recorder at all times. When a group or single individual (impala, kudu) were sighted, the car was immediately stopped. The GPS position of the car was taken, the distance to the animal(s) was measured with a LEICA LRF 900 SCAN laser rangefinders (LEITZ, Wetzlar, Germany) for distance estimation, and we recorded the total number of individuals, their sexes, ages, initial behaviours (when vehicle stopped), and finally, we took a photo. We established ten road transects, whereby nine of these have a length of $50 \mathrm{~km}$ each, and only one road transect had a length of $15 \mathrm{~km}$. In total, we drove $465 \mathrm{~km}$ of transects in October 2016 and $465 \mathrm{~km}$ in September 2017. The fieldwork lasted for 28 days each year, for a total of 56 days in which we had a total number of observations 283 of impala and 128 observations of greater kudu.

\subsubsection{Age and Sex Determination}

The ages of individuals were classified into the following classes: 1) calves (10-40\% of adult size), 2) young (50-60\% of adult size), 3) sub-adults ( $70-80 \%$ of adult size), and 4$)$ adults ( $90-100 \%$ of adult size). In cases of poor visibility, we used a pair of binoculars for classification. In a few cases where we were not able to determine the sex or age of an individual, the variable was recorded as "unknown". First, we counted all animals, and thereafter, we recorded the sex and age of individuals in a group. During analysis, we determined the sex ratio of the studied species as the ratio of adult and sub-adult females to total numbers of adult and sub-adult individuals of both sexes. Recruitment was estimated as the ratio of calves and young to adult females.

\subsubsection{Classification of Group Size}

A group was defined as any number (more than one) of individuals that were behaving in a coordinated manner, either moving together in the same direction or engaged in the same activity at any one time and were in close proximity to one another. In each group, individuals were counted, and their initial behaviour (when spotted) was noted (including feeding, vigilance, urine testing, fighting/sparring, resting and moving).

\subsubsection{Flight Initiation Distance (FID)}

Flight initiation distance (FID) refers to the distance at which an animal reacts by moving or running away from an approaching danger or vehicle, and it is assumed that an animal will make decisions considering both predation risk and potential fitness benefit (Nyahongo, 2008; Setsaas, Holmern, Mwakalebe, Stokke, \& Røskaft, 2007). Other researchers define it as an antipredator behaviour and often use FID as a measure of tolerance to different levels of threats in disturbance studies. Thus, a large FID would be expected when the chance of death or serious injury was perceived to be high (Brown et al., 2012). FID is affected by factors such as patch forage quality, reproductive state, risk of capture (e.g., distance from hiding place), speed and direction of the approaching predator, number of predators, individual fitness, group size and starting distance (the distance between predator and prey when approach begins) (Bateman \& Fleming, 2014; Holmern et al., 2016). During this study, an individual/group was spotted, and all data were recorded as described, after which we tested FID only when animals did not immediately run away from the car. We used the same method as described by Setsaas et al. (2007); one person walked towards an animal, while another person recorded distances between the person and test animal at the moment of fleeing (Holmern et al., 2016).

\subsubsection{Habitat Classification}

Habitat was classified into categories of woodland as follows: 1) trees with canopy cover $>20 \%$ ( $\mathrm{I}=>70 \%$, II $=$ $50-69 \%$, III $=20-49 \%$ ), 2) bushland (dense woody vegetation $<6 \mathrm{~m}$ in height), 3) shrubland/bushed grassland (grassland with 2-20\% bush canopy), 4) wooded grassland (grassland with 2-20\% tree cover), and 5) grassland (grass-dominated). 


\subsubsection{Behaviour}

The following behaviours were recorded: 1) feeding (feeding on vegetation or chewing the cud), 2) walking (slow gait movement from one place to another), 3) vigilance (the time an individual refrained from any other activities, scanning the surrounding environment by standing still, stretching their necks with their heads up), and 4) other behaviours (including resting, urinating, drinking, necking, and mating).

\subsection{Statistical Analyses}

We performed all statistical data analyses using Statistical Package of Social Science (IBM SPSS statistics for windows, version 19.0, Armonk, NY: IBM Corp) (Alan \& Duncan, 2011). We generated ANOVA tests and chi-square tests $\left(\chi^{2}\right)$ for comparison of the significance variations in testing the first and second hypotheses (Alan \& Duncan, 2011; Bateman \& Fleming, 2014). We used chi-square tests to assess the effects of protected area status, year and habitat on the behaviour of impala and greater kudu. We also tested for differences between independent variables (protected area status and habitat types). We performed linear regression analyses to test the interaction effects of different dependent variables, which included group size, sex ratio, recruitment rate of calves, vigilance behaviour and flight initiation distance (FID) on the following independent variables: protected area status (game reserve and national park), year and habitat preference. Statistical significance was set at $\mathrm{P}<0.05$.

\section{Results}

In total we had 283 observations of impala and 128 greater kudu. Out of 283 observations of impala $37 \%$ ( $\mathrm{n}=$ $105)$ were from RGR and $63 \%(n=178)$ of impala observation were from RNP. Among the total observation of greater kudu observations 64\% $(\mathrm{n}=82)$ came from RGR and 36\% $(\mathrm{n}=46)$ grater kudu were observed in RNP.

\subsection{Group Size}

Group size of the impala did not differ significantly between the first and second year of data collection (Table 1). Impala group size differed significantly between RGR and RNP, with a higher mean group size in RNP and fewer individuals per group in RGR (Table 2). Impala group size varied significantly between different habitats; larger group sizes were observed in grassland, followed by wooded grassland, bushland and shrubland, and the smallest group sizes were found in woodland (Table 3).

We used a linear regression analysis with impala group size as a dependent variable and then included protected area status, year and habitat as independent variables. However, protected area status $(\mathrm{t}=5.48, \mathrm{P}<0.001)$ was the only significant contributor to the observed $11.3 \%$ variation, while year $(\mathrm{t}=1.89, \mathrm{P}=0.060)$ and habitat type $(\mathrm{t}=-0.74, \mathrm{P}=0.459)$ did not add any significance in explaining the variation in impala group size.

The mean group size of greater kudu herds was significantly larger in the second year than in the first year (Table 1). Furthermore, the mean group size of greater kudu in RGR was significantly smaller than that in RNP (Table 2). Finally, the mean group size of the greater kudu did not vary between different habitats (Table 3). A linear regression analysis was performed with greater kudu group size as a dependent variable and year and protected area status as independent variables. Both protected area status $(\mathrm{t}=4.42, \mathrm{P}<0.001)$ and year $(\mathrm{t}=2.58$, $\mathrm{P}=0.010$ ) were significant contributors to the observed $18.4 \%$ variation in greater kudu group size.

Table 1. Mean group size, sex ratio, calf-to-female ratio, vigilance behaviour, and flight initiation distance in two different study years of impala and greater kudu in RGR and RNP

\begin{tabular}{|c|c|c|c|c|c|c|c|c|}
\hline \multirow[t]{2}{*}{ Species } & \multirow[t]{2}{*}{ Variables } & \multicolumn{2}{|c|}{ Year 2016} & \multicolumn{2}{|c|}{ Year 2017} & \multicolumn{3}{|c|}{ Statistical test } \\
\hline & & Mean \pm SD & $\mathrm{n}$ & Mean \pm SD & $\mathrm{n}$ & $\mathrm{F}=$ & $\mathrm{df}$ & $\mathrm{P}$ \\
\hline \multirow[t]{5}{*}{ Impala } & Group size & $9.63 \pm 8.29$ & 148 & $10.73 \pm 15.20$ & 135 & 0.59 & 1 & 0.443 \\
\hline & Sex ratio $(M / M+F)$ & $0.35 \pm 0.38$ & 148 & $0.39 \pm 0.43$ & 135 & 0.91 & 1 & 0.341 \\
\hline & Calves/females & $0.17 \pm 0.29$ & 115 & $0.13 \pm 0.22$ & 92 & 1.56 & 1 & 0.213 \\
\hline & Vigilant individuals & $0.28 \pm 0.35$ & 148 & $0.26 \pm 0.41$ & 135 & 0.35 & 1 & 0.557 \\
\hline & Flight distance (m) & $45.34 \pm 29.39$ & 148 & $65.16 \pm 40.91$ & 135 & 22.20 & 1 & $<0.001$ \\
\hline \multirow[t]{5}{*}{ Greater Kudu } & Group size & $4.16 \pm 2.14$ & 73 & $5.51 \pm 3.43$ & 55 & 7.40 & 1 & 0.007 \\
\hline & Sex ratio $(\mathrm{M} / \mathrm{M}+\mathrm{F})$ & $0.23 \pm 0.39$ & 73 & $0.28 \pm 0.33$ & 54 & 0.616 & 1 & 0.433 \\
\hline & Calves/females & $0.10 \pm 0.21$ & 59 & $0.20 \pm 0.27$ & 46 & 4.93 & 1 & 0.029 \\
\hline & $\mathrm{N}$ vigilant/ $\mathrm{N}$ total & $0.48 \pm 0.36$ & 73 & $0.47 \pm 0.46$ & 55 & 0.06 & 1 & 0.809 \\
\hline & Flight distance & $67.29 \pm 32.91$ & 73 & $76.20 \pm 33.41$ & 55 & 2.27 & 1 & 0.134 \\
\hline
\end{tabular}


Table 2. Impala and greater kudu mean differences in group size, sex ratio, calf-to-female ratio, vigilance behaviour, and flight initiation distance in RGR and RNP

\begin{tabular}{lllllllll}
\hline \multirow{2}{*}{ Species } & Variables & \multicolumn{2}{c}{ RGR } & \multicolumn{3}{c}{ RNP } & \multicolumn{3}{c}{ Statistical tests } \\
\cline { 3 - 8 } & & Mean \pm SD & $n$ & Mean \pm SD & n & F & df & P \\
\hline \multirow{2}{*}{ Impala } & Group size & $5.50 \pm 4.3$ & 105 & $12.90 \pm 14.20$ & 178 & 27.15 & 1 & $<0.001$ \\
& Sex ratio (M/M+F) & $0.35 \pm 0.42$ & 105 & $0.38 \pm 0.40$ & 178 & 0.406 & 1 & 0.524 \\
& Calves/females & $0.11 \pm 0.22$ & 77 & $0.18 \pm 0.27$ & 130 & 4.46 & 1 & 0.036 \\
& N Vigilant/N total & $0.48 \pm 0.41$ & 105 & $0.15 \pm 0.27$ & 178 & 60.47 & 1 & $<0.001$ \\
& Flight distance (m) & $93.09 \pm 30.30$ & 105 & $32.21 \pm 14.81$ & 178 & 512.34 & 1 & $<0.001$ \\
Greater Kudu & Group size & $3.95 \pm 2.18$ & 82 & $6.15 \pm 3.31$ & 46 & 20.45 & 1 & $<0.001$ \\
& Sex ratio (M/M+F) & $0.21 \pm 0.35$ & 81 & $0.33 \pm 0.38$ & 46 & 3.28 & 1 & 0.073 \\
& Calves/females & $0.08 \pm 0.19$ & 69 & $0.26 \pm 0.29$ & 36 & 14.17 & 1 & $<0.001$ \\
& N vigilant/N total & $0.61 \pm 0.38$ & 82 & $0.24 \pm 0.33$ & 46 & 31.74 & 1 & $<0.001$ \\
& Flight distance & $84.59 \pm 32.33$ & 82 & $47.11 \pm 18.08$ & 46 & 52.49 & 1 & $<0.001$ \\
\hline
\end{tabular}

Table 3. Impala and greater kudu group sizes, sex ratios, calf-to-female ratios, vigilances, and flight initiation distances versus habitat types

\begin{tabular}{|c|c|c|c|c|c|c|c|c|c|}
\hline \multirow{2}{*}{$\frac{\text { Species }}{\text { Impala }}$} & \multirow{2}{*}{$\begin{array}{l}\text { Habitat types } \\
\text { Variables }\end{array}$} & \multirow{2}{*}{$\begin{array}{l}\text { WD } \\
\begin{array}{l}\text { Mean } \pm \text { SD } \\
\mathrm{n}=59\end{array}\end{array}$} & \multirow{2}{*}{$\begin{array}{l}\text { WG } \\
\begin{array}{l}\text { Mean } \pm \text { SD } \\
n=97\end{array}\end{array}$} & \multirow{2}{*}{$\begin{array}{l}\mathrm{G} \\
\mathrm{Mean} \pm \mathrm{SD} \\
\mathrm{n}=50\end{array}$} & \multirow{2}{*}{$\begin{array}{l}\mathrm{SH} \\
\begin{array}{l}\text { Mean } \pm \text { SD } \\
\mathrm{n}=55\end{array}\end{array}$} & \multirow{2}{*}{$\begin{array}{l}\mathrm{BU} \\
\mathrm{Mean} \pm \mathrm{SD} \\
\mathrm{n}=22\end{array}$} & \multicolumn{3}{|c|}{ Statistical tests } \\
\hline & & & & & & & $\mathrm{F}$ & $\mathrm{df}$ & $\mathrm{P}$ \\
\hline & Group size & $7.47 \pm 6.30$ & $10.10 \pm 15.26$ & $14.80 \pm 14.76$ & $9.04 \pm 7.50$ & $9.82 \pm 7.58$ & 2.76 & 4 & 0.028 \\
\hline & Sex ratio $(M / M+F)$ & $0.41 \pm 0.41$ & $0.38 \pm 0.42$ & $0.34 \pm 0.41$ & $0.40 \pm 0.41$ & $0.18 \pm 0.29$ & 1.55 & 4 & 0.189 \\
\hline & Calves/females & $0.18 \pm 0.34$ & $0.14 \pm 0.23$ & $0.10 \pm 0.20$ & $0.15 \pm 0.24$ & $0.23 \pm 0.28$ & 0.92 & 4 & 0.440 \\
\hline & $\mathrm{N}$ vigilant/ $\mathrm{N}$ total & $0.39 \pm 0.42$ & $0.25 \pm 0.37$ & $0.13 \pm 0.28$ & $0.32 \pm 0.41$ & $0.24 \pm 0.35$ & 3.45 & 4 & 0.009 \\
\hline & Flight distance & $65.98 \pm 41.26$ & $67.63 \pm 39.7$ & $33.98 \pm 22.38$ & $45.18 \pm 27.63$ & $39.55 \pm 19.35$ & 11.85 & 4 & $<0.001$ \\
\hline \multirow[t]{7}{*}{ Greater kudu } & Variables & $\mathrm{n}=48$ & $\mathrm{n}=13$ & $\mathrm{n}=4$ & $\mathrm{n}=44$ & $\mathrm{n}=19$ & \multicolumn{3}{|c|}{ Statistical test } \\
\hline & & Mean & Mean & Mean & Mean & Mean & $\mathrm{F}$ & $\mathrm{df}$ & $\mathrm{P}$ \\
\hline & Group size & $4.02 \pm 2.31$ & $4.46 \pm 2.33$ & $5.50 \pm 2.89$ & $5.56 \pm 3.39$ & $4.47 \pm 2.59$ & 2.14 & 4 & 0.079 \\
\hline & Sex ratio & $0.29 \pm 0.43$ & $0.16 \pm 0.29$ & $0.10 \pm 0.11$ & $0.23 \pm 0.32$ & $0.31 \pm 0.40$ & 0.67 & 4 & 0.612 \\
\hline & Calves ratio & $0.08 \pm 0.20$ & $0.10 \pm 0.21$ & $0.22 \pm 0.31$ & $0.19 \pm 0.26$ & $0.21 \pm 0.28$ & 1.43 & 4 & 0.229 \\
\hline & $\mathrm{N}$ vigilant/ $\mathrm{N}$ total & $0.53 \pm 0.39$ & $0.54 \pm 0.40$ & $0.30 \pm 0.24$ & $0.46 \pm 0.45$ & $0.38 \pm 0.37$ & 0.73 & 4 & 0.572 \\
\hline & Flight distance & $72.65 \pm 30.01$ & $88.46 \pm 25.77$ & $43.75 \pm 13.77$ & $67.07 \pm 34.21$ & $70.53 \pm 42.03$ & 1.79 & 4 & 0.135 \\
\hline
\end{tabular}

WD (woodland), WG (wooded grassland), G (grassland), SH (shrubland), and BU (bushland).

\subsection{Sex Ratio}

The impala and greater kudu sex ratios did not vary significantly between different years (Table 1), protected area statuses (Table 2) or between different habitats types (Table 3).

\subsection{Calf Recruitment}

Impala calf recruitment rates did not vary significantly between different years or habitat types (Tables 1,3 ). However, calf recruitment rate differed significantly between protected areas, with much fewer mean calves per adult female in RGR compared to RNP (Table 2).

For greater kudu, the mean number of calves per adult female differed significantly between years, with a higher ratio during the second year (Table 1). Greater kudu calf recruitment ratio also varied between the two protected areas. The calf-to-female ratio in RGR was lower than the recruitment of calves in RNP (Table 2). Mean calf recruitment of greater kudu did not vary significantly between habitat types (Table 3).

A linear regression analysis was completed, with greater kudu calves ratio as a dependent variable and protected area status and year as independent variables. Only protected area $(\mathrm{t}=3.38, \mathrm{P}<0.001)$ contributed to the observed $14.2 \%$ variation, while year $(\mathrm{t}=1.28, \mathrm{P}=0.202)$ did not add any significance to the observed variation.

\subsection{Behaviour}

In RGR, out of 105 total observations, $15.2 \%(n=16)$ impala started running immediately once the vehicle was stopped or they heard the sound of the car, while $21.0 \%(\mathrm{n}=22)$ were vigilant. In RNP, out of 178 observations, we observed only $2.8 \%(n=5)$ impala running when the car stopped, and $1.1 \%(n=2)$ were vigilant, a 
significant difference $\left(\chi^{2}=59.0, \mathrm{df}=4, \mathrm{P}<0.001\right)$. Behaviour did not differ between different habitat types: woodland $(10.2 \%$ running, $\mathrm{n}=6)$, wooded grassland $(8.2 \%$ running, $\mathrm{n}=8)$, grassland $(6 \%$ running, $\mathrm{n}=3)$, shrubland (3.6\% running, $\mathrm{n}=2)$ and bushland $(9.1 \%$ running, $\mathrm{n}=2)\left(\chi^{2}=23.4, \mathrm{df}=16, \mathrm{P}=0.103\right)$.

The mean numbers of vigilant impala per group did not vary significantly between years (Table 1). A correlation test between the number of vigilant impalas and group size indicated a negative correlation (rho $=-0.237, \mathrm{P}<$ 0.001). RGR had a higher number of vigilant individuals per group than did RNP (Table 2). The number of vigilant impala varied significantly between different habitats, with most vigilant individuals found in woodland, followed by wooded grassland, shrubland and bushland, with lowest mean vigilance in grassland (Table 3 ).

A linear regression analysis with the number of vigilant impala individuals as a dependent variable and group size, protected area status, year and habitat as independent variables indicated that protected area status $(\mathrm{t}=-6.99$, $\mathrm{P}<0.001)$ and group size $(\mathrm{t}=2.86, \mathrm{P}=0.005)$ significantly explained the $22.4 \%$ variation in vigilance behaviour of impala, while habitat $(\mathrm{t}=1.36, \mathrm{P}=0.214)$ and year $(\mathrm{t}=-1.92, \mathrm{P}=0.056)$ did not add any significance difference to the observed variations.

Greater kudu behaviour differed between RGR and RNP, as slightly more than half of the greater kudu in RNP were feeding $(54.3 \%, \mathrm{n}=25)$, while only $26.8 \%(\mathrm{n}=22)$ were feeding in $\mathrm{RGR}\left(\chi^{2}=18.1, \mathrm{df}=4, \mathrm{P}=0.001\right)$. The behaviour of greater kudu did not vary significantly with any habitat, including woodland $(37.5 \%$ feeding, $\mathrm{n}$ $=18)$, wooded grassland ( $38.5 \%$ feeding, $\mathrm{n}=5)$, grassland ( $75 \%$ feeding, $\mathrm{n}=3)$, shrubland $(27.3 \%$ feeding, $\mathrm{n}=$ $12)$ and bushland ( $42.1 \%$ feeing, $\mathrm{n}=8)\left(\chi^{2}=2.22, \mathrm{df}=16, \mathrm{P}=0.137\right)$.

There was no significant difference in the mean vigilance of greater kudu between years (Table 1). The number of vigilant greater kudu correlated negatively with group size (rho $=-0.55, \mathrm{P}<0.001)$. We recorded a significantly higher number of vigilant individuals in RGR compared to RNP (Table 2). There was no significant difference between mean numbers of vigilant greater kudu in different habitat types (Table 3).

A linear regression analysis with group size, year, protected area status and habitat as independent variables and number of vigilant greater kudus as a dependent variable revealed that group size $(t=-5.72, P<0.001)$ and protected area status $(\mathrm{t}=-3.63, \mathrm{P}<0.001)$ significantly contributed to the observed $16 \%$ variation in vigilance behaviour of greater kudu, while habitat $(\mathrm{t}=-0.04, \mathrm{P}=0.966)$ and year $(\mathrm{t}=1.40, \mathrm{P}=0.163)$ had no significance.

\subsection{Flight Initiation Distance (FID)}

The mean distance at which impala ran away from the vehicle was significantly longer in the second year than in the first year (Table 1). The mean FID of impala was significantly longer in RGR compared to RNP (Table 2). The average FID of impala also varied with habitat, as it was significantly longer in wooded grassland, followed by woodland, shrubland and bushland and was lowest in grassland (Table 3 ).

A linear regression analysis with flight initiation distance as a dependent variable and year and protected area status and habitat as independent variables revealed that year and protected area status significantly contributed to the observed $66 \%$ variation in impala FID (protected area status: $\mathrm{t}=-20.69, \mathrm{P}<0.001$; year: $\mathrm{t}=2.65, \mathrm{P}=$ 0.009 ), while habitat $(\mathrm{t}=1.28, \mathrm{P}=0.201)$ did not contribute significantly to the variation.

The mean FID of greater kudu did not differ between years (Table 1). Greater kudu in RNP had significantly lower mean FID than did individuals in RGR (Table 2). The FID of greater kudu did not vary significantly between habitat types (Table 3).

A linear regression revealed that both protected area status and year significantly contributed to the observed $32.4 \%$ variation in FID of greater kudu (protected area status: $\mathrm{t}=-7.53, \mathrm{P}<0.001$; year: $\mathrm{t}=2.36, \mathrm{P}=0.020$ ).

\section{Discussion}

\subsection{Group Size}

The group sizes of both impala and greater kudu were larger in RNP compared to RGR, probably due to the differences in the nature of tourism activities conducted in these two protected areas. Furthermore, Matthias Waltert et al. (2011) reported lower group size of mammals in a hunted area (game reserve) compared to a non-hunted population (national park) in western Tanzania. Similar findings of differences in mean group sizes of impala were found in east Ugalla (less hunting pressure) and west Ugalla (more hunting pressure) in western Tanzania (Wilfred \& MacColl, 2016). The smaller group sizes in RGR might be due to the direct effects of trophy hunting, as well as behavioural responses resulting in animals selecting safer habitats further from roads, which are frequently used by hunters. Larger group sizes were observed in the greater kudu populations during the second study year, which might suggest less hunting impact during this period. However, no changes in impala group sizes were recorded between years, and these differences are therefore difficult to interpret. 
We found no effect on habitat in greater kudu; however, impala group size was larger in wooded grassland habitats. This difference might have been because impala preferred this habitat for feeding along the rivers where they drink water. Thus, our first hypothesis, that we expect smaller group sizes in RGR than in RNP in both impala and greater kudu, was supported, while our second hypothesis, that there should be no differences between different habitats, was supported by greater kudu observations only. Further testing is necessary to better understand the effect of habitat type on impala group size.

\subsection{Sex Ratio}

Our results do not support the hypothesis that hunting skews sex ratios towards females. However, unlike our findings the other researchers Marealle, Fossøy, Holmern, Stokke, and Røskaft (2010) reported a female-skewed sex ratio in high poaching risk areas in the Serengeti ecosystem. Furthermore, Milner et al. (2007) reported a female-biased sex ratio in a hunted population. Wilfred and MacColl (2016) found a more pronounced female-skewed sex ratio of mammals in Ugalla Game Reserve (trophy hunting) than in the Katavi National Park (ecotourism). Ndibalema (2009) found a female-biased sex ratio in wildebeest (Connochaetes taurinus), and Magige, Holmern, Stokke, Mlingwa, and Røskaft (2009) reported a female-biased sex ratio in ostrich (Struthio camelus) in the Serengeti ecosystem. Thus, the Serengeti, an area with high poaching activity, had more female-skewed sex ratios as compared to areas with low poaching activity, which is similar to our results. Our first hypothesis, that we expected a more female-biased sex ratio in RGR than in RNP in both impala and greater kudu, was not supported, while the second hypothesis, that there will be no differences between different habitats, was also supported.

\subsection{Calf Recruitment}

The recruitment of calves for both impala and greater kudu was lower in RGR than in RNP. Selective removal through trophy hunting probably affects the mammals' fitness by lowering the recruitment rate via either higher calf mortality or lower fecundity, when the proportion of males is below a tolerable threshold in the hunted population (Milner et al., 2007). Selective harvesting by trophy hunters might have negative effects on mammal populations by reducing calf recruitment if the proportion of males harvested goes below the accepted threshold (Milner et al., 2007). However, if hunting is well controlled, there will be less harm to the calves, as in species such as impala, one adult male may be capable of impregnating several adult females (Caro et al., 1998; Milner et al., 2007). On the other hand, trophy hunting disturbances reduce feeding opportunities and increase the level of stress (Benhaiem et al., 2008). Such disturbances may reduce the body conditions that result in reduced breeding efforts, lowering calf survival (Milner et al., 2007). Temporal variation over years was only found in the greater kudu population. We found higher mean recruitment rates in the second year. This might have been because the data in the second year were collected in August and September, whereas data in the first year were collected in October. The difference between years might have been due to the fact that data collection in the second year was closer to the months of March-April, which are the months when most calving occurs in greater kudu, which might have contributed to the observation of more young in the second year compared to the first. We hypothesised that there would be differences in recruitment of calves/young (i.e., a lower calf-to-female ratio in RGR than in RNP). This hypothesis was supported; however, we had also hypothesised that habitat would have no effect on calf recruitment, and our results also supported this idea. Our results might well indicate that Ruaha is an important resource for the Rungwa impala and kudu populations, a hypothesis that needs further testing.

\subsection{Behaviour}

The majority of impala and greater kudu groups were more vigilant and fleeing at longer distances in RGR. This supports our hypothesis that mammals in the RGR would show more vigilance behaviour than those in RNP. A study in western France found an increased vigilance level in a hunted roe deer (Capreolus capreolus) population (Benhaiem et al., 2008). Animals were more relaxed in RNP, where we found feeding behaviour, followed by resting, to be the dominant behaviour in impala groups. In contrast, the dominant behaviour in RGR was running, followed by feeding. This is most likely due to the difference in disturbance levels, resulting in the fact that the studied RGR animals devote less time to feeding in a highly disturbed area. The French study found that roe deer trade off risk avoidance for food availability and spend more time vigilant during hunting season (Benhaiem et al., 2008). Trophy hunting causes more disturbance to wild mammals than does game viewing and photographic tourism activities, which have comparatively less disturbance on wild mammal behaviour and stress level (Allendorf \& Hard, 2009; Hunninck et al., 2017; Lunde et al., 2016; Marealle \& Røskaft, submitted; Setsaas et al., 2007). We also found support for our hypothesis that there should be no differences in behaviour between habitats. 
The flight initiation distance was much higher in the hunting area (RGR). The antipredator behaviour of the RGR impala and greater kudu might have been shaped by game hunting, as we observed larger mean FID there compared to RNP. Hunninck et al. (2017) found that elephants are more stressed outside the national park than those within the Etosha National Park in Namibia and Holmern et al. (2016) in the Serengeti National Park. Findings by Brown et al. (2012) in the Grand Teton National Park in northwestern Wyoming, USA, indicated that elk (Cervus elaphus) and pronghorn (Antilocapra americana) were responsive towards passing vehicles. Impala FID was much higher in the second year of data collection of our study. The difference between years might have been because when data was collected in the second year, the hunting season was at its peak in RGR, with a subsequent higher level of disturbance. There was no difference between years in the RNP population. Habitat types influenced FID in impala, with higher FID in wooded grassland; this might have been because a greater proportion of impala observations were made in this habitat type, which thereby influenced the observed variations in FID. Thus, our second hypothesis was partly supported, but no differences were observed between habitat types for greater kudu.

\section{Conclusion and Recommendations}

Data on animal group size, sex ratio, recruitment rate, behaviour and their flight initiation distances are important in determining the impacts of disturbances on animal populations. Our results indicate that in hunted populations, animals showed clear signs of disturbance, as they had smaller group sizes, lower calf recruitment rates and were more nervous than conspecifics in the absence of trophy hunting in RNP. An implication of this might be that RGR is dependent on RNP for recruitment or, alternatively, that we might expect a dramatic decline in hunted populations in Rungwa. However, this conclusion needs further testing and long-term monitoring. Studies similar to ours may be useful to assess how activities associated with different types of protected areas may influence animal stress, behaviour and key demographic parameters. Furthermore, these effects represent important considerations for managers setting hunting quotas.

\section{Acknowledgements}

We are thankful to the EU Horizon-2020 financed project under GA 641918 (AfricanBioServices) for funding the write up of this research. Furthermore, we extend our gratitude to the Tanzania Wildlife Management Authority (TAWA), Tanzania National Parks (TANAPA), and the Tanzania Wildlife Research Institute (TAWIRI) for granting us the access to conduct this research study. We would also like to extend our thanks to Maulid Mdaki, Onesmo Mwakabejela, Jaredy Makongoro, David Kyangi, Samwel Pere Mollel and Rajabu Kamota for assistance in the field.

\section{References}

Alan, B., \& Duncan, C. (2011). Quantitative Data Analysis with IBM SPSS 17, 18 and 19: A Guide for Social Scientists. New York: Routledge.

Allendorf, F. W., \& Hard, J. J. (2009). Human-induced evolution caused by unnatural selection through harvest of wild animals. Proceedings of the National Academy of Sciences of the United States of America, 106, 9987-9994. http://dx.doi.org/10.1073/pnas.0901069106

Averbeck, C. (2002). Population ecology of impala (Aepyceros melampus) and community-based wildlife conservation in Uganda. Technische Universität München. Retrieved from http://tumb1.biblio. tumuenchen.de/publ/diss/ww/2002/averbeck.html

Averbeck, C., Apio, A., Plath, M., \& Wronski, T. (2009). Hunting differentially affects mixed-sex and bachelorherds in a gregarious ungulate, the impala (Aepyceros melampus). African Journal of Ecology, 48, 255-264. http://dx.doi.org/10.1111/j.1365-2028.2009.01118.x

Balakrishnan, M., \& Ndhlovu, D. (1992). Wildlife utilization and Local people: a case study in upper Lupande Game Management Area, Zambia. Environmental Conservation, 19(2), 135-144. http://dx.doi.org/10.1017/ S0376892900030617

Baldus, R. D., \& Cauldwell, A. E. (2004). Tourist hunting and its role in development of wildlife management areas in Tanzania. Paper presented at the Sixth International Game Ranching Symposium, Paris, France. Retrieved from http://www.wildlife-baldus.com/download/hunting_wma.pdf

Bateman, P. W., \& Fleming, P. A. (2014). Living on the edge: effects of body size, group density and microhabitat selection on escape behaviour of southern leopard frogs Lithobates sphenocephalus. Current Zoology, 60(6), 712-718. http://dx.doi.org/10.1093/czoolo/60.6.712

Benhaiem, S., Delon, M., Lourtet, B., Cargnelutti, B., Aulagnier, S., Hewison, A. J. M., ... Verheyden, H. (2008). Hunting increases vigilance levels in roe deer and modifies feeding site selection. Animal Behaviour, 76(3), 611-618. http://dx.doi.org/10.1016/j.anbehav.2008.03.012 
Brown, C. L., Hardy, A. R., Barber, J. R., Fristrup, K. M., Crooks, K. R., \& Angeloni, L. M. (2012). The effect of human activities and their associated noise on ungulate behavior. Plos One, 7(7). http://dx.doi.org/10. 1371/journal.pone.0040505

Caro, T. M., Pelkey, N., Borner, M., Severre, E. L. M., Campbell, K. L. I., Huish, S. A., ... Woodworth, B. L. (1998). The impact of tourist hunting on large mammals in Tanzania: an initial assessment. African Journal of Ecology, 36(4), 321-347. http://dx.doi.org/10.1046/j.1365-2028.1998.00146.x

de Garine-Wichatitsky, M., Fritz, H., Gordon, I. J., \& Illius, A. W. (2004). Bush selection along foraging pathways by sympatric impala and greater kudu. Oecologia, 141(1), 66-75. http://dx.doi.org/10.1007/s00442-004 -1630-3

Festa-Bianchet, M., \& Apollonio, M. (2003). Exploitative wildlife management as a selective pressure for life-history evolution of large mammals Animal behavior and wildlife conservation (pp. 191-207). Washington, Covelo, London: Island Press.

Gereta, E. (2010). The role of biodiversity conservation in development of the tourism industry in Tanzania. In E. E. Gereta, \& E. Røskaft (Eds.), Conservation of natural resources; Some African \& Asian examples (pp. 23-49). Trondheim: Tapir academic press.

Ginsberg, J. R., \& Milner Gulland, E. J. (1994). Sex biased harvesting and population dynamics in ungulates: Implications for conservation and sustainable use. Conservation Biology, 8(1), 157-166. http://dx.doi.org/10. 1046/j.1523-1739.1994.08010157.x

Hariohay, K. M., Fyumagwa, R. D., Kideghesho, J. R., \& Røskaft, E. (2017). Assessing crop and livestock losses along the Rungwa-Katavi Wildlife Corridor, South-Western Tanzania. International Journal of Biodiversity and Conservation, 9(8), 273-283. http://dx.doi.org/10.5897/IJBC2017.1116

Hoffmann, M. (2016). IUCN SSC Antelope Specialist Group: Assessment of Tragelaphus strepsiceros, greater kudu. Retrieved 20.12.2017, 2017, from http://www.iucnredlist.org

Holmern, T., Setsaas, T. H., Melis, C., Tufto, J., \& Røskaft, E. (2016). Effects of experimental human approaches on escape behavior in Thomson's gazelle (Eudorcas thomsonii). Behavioral Ecology, 27(5), 1432-1440. http://dx.doi.org/10.1093/beheco/arw052

Hunninck, L., Ringstad, I. H., Jackson, C. R., May, R., Fossøy, F., Uiseb, K., ... Røskaft, E. (2017). Being stressed outside the park-conservation of African elephants (Loxodonta africana) in Namibia. Conservation Physiology, 5(2017), 11. http://dx.doi.org/10.1093/conphys/cox067

Jarman, P. J., \& Jarman, M. V. (1973). Social behaviour, population structure and reproductive potential in impala. East African Wildlife Journal, 11, 329-338. http://dx.doi.org/10.1111/j.1365-2028.1973.tb00097.x

Kideghesho, J. R. (2015). Realities on deforestation in Tanzania: trends, drivers, implications and the way forward. Precious Forests-Precious Earth, 2017(21.12). http://dx.doi.org/10.5772/61002

Kideghesho, J. R., Nyahongo, J. W., Hassan, S. N., Thadeo, C., \& Mbije, N. E. (2006). Factors and ecological impacts of wildlife habitat destruction in the Serengeti ecosystem in northern Tanzania. Ajeam Ragee. Retrieved 27.08, 2017, from https://pdfs.semanticscholar.org/01a0/e19b0229abe4e8a984f3399d3f3e1e23ae3d.pdf

Kie, J. G. (1999). Optimal foraging and risk of predation: Effects on behavior and social structure in ungulates Mammalogy, 80(4), 1114-1129. doi: http://dx.doi.org/10.2307/1383163

Lindsey, P. A., Balme, G. A., Funston, P., Henschel, P., Hunter, L., Madzikanda, H., ... Nyirenda, V. (2013). The trophy hunting of African lions: Scale, current management practices and factors undermining sustainability. Plos One, 8(9). http://dx.doi.org/10.1371/journal.pone.0073808

Love, O. P., Chin, E. H., Wynne-Edwards, K. E., \& Williams, T. D. (2005). Stress hormones: A link between maternal condition and sex-biased reproductive investment. American Naturalist, 166(6), 751-766. http://dx.doi.org/10.1086/497440

Loveridge, A. J., Searle, A. W., Murindagomo, F., \& MacDonald, D. W. (2007). The impact of sport-hunting on the population dynamics of an African lion population in a protected area. Biological Conservation. Retrieved 11.01, 2018, from http://www.sciencedirect.com/science/journal/00063207

Lunde, E. T., Bech, C., Fyumagwa, R. D., Jackson, C., \& Røskaft, E. (2016). Assessing the effect of roads on impala (Aepyceros melampus) stress levels using faecal glucocorticoid metabolites. African Journal of Ecology, 54(4), 434-441. http://dx.doi.org/10.1111/aje.12302

Magige, F., Holmern, T., Stokke, S., Mlingwa, C., \& Røskaft, E. (2009). Does illegal hunting affect density and behaviour of African grassland birds? A case study on ostrich (Struthio camelus). Biodiversity and Conservation, 18(5), 1361-1373. http://dx.doi.org/10.1007/s10531-008-9481-6

Marealle, W. N., Fossøy, F., Holmern, T., Stokke, B. G., \& Røskaft, E. (2010). Does illegal hunting skew Serengeti wildlife sex ratios? Wildlife Biology, 16(4), 419-429. doi: http://dx.doi.org/10.2981/10-035 
Marealle, W. N., \& Røskaft, E. (submitted). Factors affecting group size and vigilance behaviour of Maasai giraffe (Giraffa camelopardalis tippelskirchi) in the Serengeti-Ngorongoro ecosystem, Tanzania. African Journal of Ecology, submitted.

Marshal, J. P., Grange, S., \& Marneweck, D. (2012). Seasonal variation in body condition of impala at Manyeleti Game Reserve, South Africa. South African Journal of Wildlife Research, 42(2), 128-137. http://dx.doi.org/ $10.3957 / 056.042 .0212$

Milner, J. M., Nilsen, E. B., \& Andreassen, H. P. (2007). Demographic side effects of selective hunting in ungulates and carnivores. Conservation Biology, 21(1), 36-47. http://dx.doi.org/10.1111/j.1523-17 39.2006.00591.x

MNRT. (2011). Rungwa-Kizigo-Muhesi Game Reserves general management plan. Dar es Salaam: Government printers.

Ndibalema, V. G. (2009). A comparison of sex ratio, birth periods and calf survival among Serengeti wildebeest sub-populations, Tanzania. African Journal of Ecology, 47(4), 574-582. http://dx.doi.org/10.1111/j. 1365-2028.2008.00994.x

Nyahongo, J. W. (2008). Flight initiation distances of five herbivores to approaches by vehicles in the Serengeti National Park, Tanzania. African Journal of Ecology, 46(2), 227-229. http://dx.doi.org/10.1111/j.1365-2028. 2007.00818.x

Okello, M. M., \& Yerian, S. (2009). Tourist satisfaction in relation to attractions and implications for conservation in the protected areas of the Northern Circuit, Tanzania. Journal of Sustainable Tourism, 17(5), 605-625. http://dx.doi.org/10.1080/09669580902928450

Setsaas, T. H., Holmern, T., Mwakalebe, G. G., Stokke, S., \& Røskaft, E. (2007). How does human exploitation affect impala populations in protected and partially protected areas? a case study from the Serengeti ecosystem, Tanzania. Biological Conservation, 136(4), 563-570. http://dx.doi.org/10.1016/j.biocon. 2007.01.001

TAWIRI. (2010). Aerial census in the Serengeti ecosystem (C. I. a. M. Unit, Trans.). Arusha: Tanzania Wildlife Research Institute.

Tingvold, H. G., Fyumagwa, R., Baardsen, L. F., Rosenlund, H., Bech, C., \& Røskaft, E. (2013). Determining adrenocortical activity as a measure of stress in African elephants (Loxodonta africana) in relation to human activities in Serengeti ecosystem. African Journal of Ecology, 51, 580-589. http://dx.doi.org/10.11 11/aje, 12069

Tuomainen, U., \& Candolin, U. (2010). Behavioural responses to human-induced environmental change. Biological Reviews. http://dx.doi.org/10.1111/j.1469-185X.2010.00164.x

URT. (2013). Population and housing census counts 2012. Retrieved 7th February, 2018, from http://www.nbs.go.tz/projections/dodoma_projections.pdf

Waltert, M., Meyer, B., \& Kiffner, C. (2011). Habitat availability, hunting or poaching: what affects distribution and density of large mammals in western Tanzanian woodlands? African Journal of Ecology, 47(4), 737-746. doi: http://dx.doi.org/10.1111/j.1365-2028.2009.01080.x

Waltert, M., Meyer, B., Shanyangi, M. W., balozi, J. J., Kitwara, O., Qolli, S., ... Muhlenberg, M. (2008). Foot surveys of large mammals in woodlands of western Tanzania. Journal of Wildlife Management, 72(3), 603610. doi: http://dx.doi.org/10.2193/2006-456

Whitman, K., Starfield, A. M., Quadling, H. S., \& Packer, C. (2004). Sustainable trophy hunting of African lions. Nature, London, 428(6979), 175-178. http://dx.doi.org/10.1038/nature02395

Wilfred, P., \& MacColl, A. D. C. (2016). Status of wildlife at trophy hunting sites in the Ugalla Game Reserve of Western Tanzania. Tropical Conservation Science, 1-10. http://dx.doi.org/10.1177/1940082916667336

Wronski, T. (2002). Feeding ecology and foraging behaviour of impala (Aepyceros melampus) in lake Mburo National Park, Uganda. African Journal of Ecology, 40(3), 205-211. http://dx.doi.org/10.1046/j.1365-2028. 2002.00348.x

\section{Copyrights}

Copyright for this article is retained by the author(s), with first publication rights granted to the journal.

This is an open-access article distributed under the terms and conditions of the Creative Commons Attribution license (http://creativecommons.org/licenses/by/4.0/). 